\title{
Kearifan Lokal dan Hambatan Inovasi Pertanian Suku Pedalaman Arfak di Kabupaten Manokwari Papua Barat
}

\section{Local Wisdom and Agriculture Innovation Obstacle of The Upland Arfak Tribal Group in Manokwari Regent West Papua}

\author{
Mulyadi $^{*}$, Basita G. Sugihen ${ }^{2}$, Pang S. Asngari ${ }^{2}$, dan Djoko Susanto ${ }^{3}$ \\ ${ }^{1}$ Fakultas Pertanian Universitas Papua \\ ${ }^{2}$ Dosen Dept. Sains Komunikasi dan Pengembangan Masyarakat FEMA IPB \\ ${ }^{3}$ Pusat Penelitian Gizi Departemen Kesehatan
}

\begin{abstract}
West Papua has the various natural resources and the human resources which have not yet been empowered optimally. Although the agriculture activities has been introduced for a long time, the subsistens agriculture has still dominated in the Arfak Tribal Group agriculture system. In their agriculture activities, the new innovation has been adopted for a short time. The new innovation on agricultural system has been considered as a disturbance of their conservative norms. But this theory disagreed by Boef et al. (1993:206) as noted that the conservative system is not the cause but the top down agriculture program which contradicted with the local wisdoms. This research is aimed to: to find the knowledge system and the local technology of Arfak people, and identify the social culture values (norms, traditional system, custom) both the supporting and the obstructing the farm of Arfak people. The results of the research showed that: (1) The Arfak tribe (people) have the indegenous knowledge to protect and to concervate the forest and to defend the food stability by the three ways, i.e (a) The three period planting, (b) multiplecrop system, (c) the natural food barn. (2) Much of the economic income has been used to fullfilled the requirements of the traditions as marrying, death, punishment of the tradition, and local fest. They are also fear to go out by the home because they believe to the supernatural power as called "Swanggi" which sent by the other village people.
\end{abstract}

Key words: local wisdom, agriculture innovation

\section{PENDAHULUAN}

Berdasarkan peta bencana alam Indonesia, Provinsi Papua dan Papua Barat relatif jarang terjadi, terutama bencana kelaparan. Berarti masyarakat tersebut memiliki kecukupan bahan pangan. Pangan diperoleh dari alam (meramu) dan bercocok tanam umbi-umbian sebagai makanan pokok dan sayur-sayuran sebagian dijual untuk mendapatkan uang. Mengapa pertanian tradisional mampu menyediakan pangan dan pada Desember 2005 Kabupaten Yahukimo terjadi kelaparan? Pertanyaan kontradiktif ini yang ingin dijawab dalam tulisan ini.

\footnotetext{
${ }^{1}$ Korespondensi Penulis. Telepon: 08124834515
}

Terdapat dua segregasi tipe pembangunan pertanian di Papua yaitu pertanian tradisional lokal yang dilakukan oleh penduduk atau suku asli seperti masyarakat Arfak di Kabupaten Manokwari, Provinsi Papua Barat dan pertanian modern yang membawa inovasi teknologi diwakili oleh transmigran, penyuluh pemerintah, dan misionaris. Namun inovasi dari luar mendominasi (otoritas) proses integrasi sehingga tidak memberi ruang berkembangnya teknologi lokal tradisional. Akibatnya, tidak jarang terjadi gangguan (disonansi) proses adopsi dan berakhir dengan penolakan (rejection) atau berhenti (dis-continuansi) menggunakan inovasi tersebut.

Penggunaan teknologi modern dalam pembangunan pertanian (revolusi hijau), diakui dapat meningkatkan produksi pertanian secara cepat, namun pada panen 
berikutnya produksi pertanian menjadi menurun kembali sejalan dengan terjadinya degradasi kualitas lingkungan yang nyata dan laten. Salah satu contoh kerusakan lingkungan sebagai dampak negatif dari pembangunan pertanian diungkapkan oleh Intan Achmad (Soedijanto, 2004:4) dan Untung (1996:2), bahwa akibat penggunaan pestisida berlebihan maka 500 spesies serangga menjadi resisten terhadap penggunaan berbagai jenis pestisida. Beberapa serangga diramalkan akan muncul menjadi monster yang sangat menakutkan karena sudah kebal terhadap pemakaian semua pestisida. Dampak pada lingkungan adalah dapat meningkatkan erosi tanah dan air, penurunan kesuburan tanah karena pengurangan kadar unsur hara, salinasi, peningkatan keasaman tanah, dan meningkatnya kepadatan tanah.

Ternak babi di Papua dan kerbau di Sumatera merupakan alat penarik bajak dan sumber tabungan petani. Semula berperan sebagai tenaga bantu manusia yang utama dalam mengolah sawah, sekarang menjadi kurang diperhatikan lagi. Hal ini berakibat terhadap menurunnya populasi ternak itu. Akibat selanjutnya adalah menurunnya sumber pupuk kandang yang murah serta produk lain dari hewan tersebut yang bisa menunjang pendapatan dan sumber daya investasi bagi petani (Adimihardja, 2004:8).

Pelajaran buruk di atas, membangun pertanian dan perdesaan secara berkelanjutan sudah saatnya kembali melirik pengetahuan dan teknologi lokal atau sering disebut kearifan lokal (local wisdom). Karena kearifan lokal memegang peranan penting dalam pengelolaan sumber daya alam, manusia dan sosial. Terlihat pada proses interaksi msya- rakat yang sejak beberapa generasi telah hidup dari pengelolaan sumberdaya alam. Interaksi masyarakat dengan sumberdaya alam selalu didasarkan pada nilai-nilai, norma-norma, dan adat istiadat. Hal ini terlihat dari pola pembukaan kebun baru secara gotong royong dalam mengerjakan lahan, penghormatan hak adat atas batas tanah dan hutan dari masing-masing suku atau marga, pola bertani, memper-tahankan hidup, dan pelestarian lingkungan (Cohen dan Prusak, 2001:90-95)

Menemukan ilmu pengetahuan dan teknologi pertanian lokal sebagai alternatif pembangunan pertanian di Provinsi Papua Barat adalah alasan penting dilakukan penelitian ini. Rumusan masalah penelitian adalah: apakah masyarakat Arfak memiliki sistem pengetahuan dan teknologi lokal (local wisdom) yang mendukung pembangunan pertanian? mengapa masyarakat Arfak cenderung mempertahankan inovasi yang dimiliki sendiri dan menolak inovasi yang datang dari luar? Tujuan penelitian ini adalah untuk mengungkap: sistem pengetahuan dan teknologi pertanian lokal masyarakat Arfak. Faktor-faktor pendukung dan penghambat proses adopsi inovasi pada masyarakat Arfak terkait dengan kearifan lokal.

\section{METODE PENELITIAN}

Populasi penelitian ini adalah kepala keluarga petani (laki-laki atau perempuan) yang berasal dari suku besar Pedalaman Arfak yang terdiri dari empat sub suku bangsa yaitu: Hatam, Meyakh, Sougb, dan Moule. Mereka adalah suku asli yang tinggal di sekitar Pegunungan Arfak di Kabupaten Manokwari, Provinsi Papua Barat. Setelah pemekaran tahun 2005 Kabupaten Manokwari terdiri dari 29 distrik/kecamatan, terbagi menjadi 13 distrik di daerah pedalaman atau dataran tinggi dan 16 distrik di daerah dataran rendah dan pesisir.

Penentuan responden dalam penelitian ini dilakukan dengan pembagian wilayah yang disengaja (area sampling and purposive) dengan alasan sesuai dengan obyek penelitian yaitu memilih distrik, tempat penyebaran empat suku besar Arfak (Hatam, Meyakh, Sougb, Moule), dan kampung yang memiliki kegiatan bercocok tanam ubi jalar dan sayur-sayuran sebagai mata penca-harian pokok masyarakat 
Arfak, dan pernah dilakukan responden (termasuk responden kunci program/proyek pertanian oleh pemerintah. terdiri dari Kepala Suku, Tokoh Berdasarkan alasan tersebut diperoleh Agama/Misionaris, dan Kepala Kam-pung). sampel sebagai berikut: 4 distrik Penelitian berlangsung pada bulan April s/d (Manokwari Utara, Warmare, Minyambow, September 2006 (Tabel 1).

dan Survey), 10 kampung, dan 100

Tabel 1. Jumlah Unit Pengamatan Berdasarkan Lokasi

\begin{tabular}{llllc}
\hline $\begin{array}{l}\text { Suku } \\
\text { Dominan }\end{array}$ & Wilayah & Distrik & Kampung & $\begin{array}{c}\text { Unit Pengamatan } \\
\text { (KK petani) }\end{array}$ \\
\hline Meyakh & Dataran Rendah & Manokwari Utara & Yom Nuni & 10 \\
& & & Sairo & 10 \\
\multirow{2}{*}{ Moile } & Dataran Tinggi & Minyambow & Bremi & 10 \\
& & & Anggra & 10 \\
Sough & Dataran Tinggi & \multirow{2}{*}{ Serurey } & Mbenti & 10 \\
& & & Serurey & 10 \\
Hatam & Dataran Rendah & \multirow{2}{*}{ Warmare } & Saug Bameba & 10 \\
& & & Hink & 10 \\
& & & Tanah Merah & 10 \\
\hline \multirow{2}{*}{ Jumlah } & & 4 Distrik & Guentui & 10 \\
\hline
\end{tabular}

Penelitian dilakukan dengan metode penelitian survei yang bersifat deskriptif kuantitatif dan deskriptif kualitatif. Deskriptif kuantitatif adalah berupaya menjelaskan dan menguraikan fenomena yang diamati ketika melakukan pengujian hipotesa. Deskriptif kualitatif adalah berusaha menjelaskan dan menguraikan fenomena yang dihasilkan dalam kegiatan pengamatan secara eksploratif pada obyek kegiatan pertanian pada Suku Pedalaman Arfak. Oleh karena itu, penelitian ini selain bersifat mengembangkan fenomena juga untuk menemukan faktor-faktor penghambat dan pendukung adopsi inovasi. Data yang dihasilkan digolongkan menjadi dua, yaitu data utama yang menggunakan metode kualitatif dan penunjang menggunakan metode kuantitatif. Data kualitatif dilakukan dengan metode eksplorasi yaitu menggali informasi melalui teknik pengamatan pada kegiatan pertanian khususnya bercocok tanam ubi jalar seperti penentuan waktu tanam sampai dengan pasca panen. Data kuantitatif terkait dengan: Nilai-nilai Sosial Budaya dan Atribut Inovasi.

Data primer diperoleh dengan teknik observasi non partisipatif (nonparticipatory observation), wawancara mendalam dan diskusi. Teknik ini didukung oleh sejumlah instrumen atau alat: kuesioner dan alat rekaman seperti tape recorder, kamera photo dan video sebagai bahan analisis, evaluasi dan dokumentasi saat penulisan laporan. Data peubah pengetahuan dan teknologi lokal diperoleh dengan teknik observasi dan wawancara mendalam. Data diamati dalam bentuk kata-kata dan tindakan/perilaku, selebihnya adalah data tambahan seperti dokumen dan lain-lain. Observasi dengan berada di suatu tempat, misalnya di kebun/ladang, tempat aktivitas utama petani bercocok tanam ubi jalar. Peneliti duduk dan diam mengamati sepanjang kegiatan yang dilakukan oleh petani. Mereka mengerjakan apa, berapa lama, berapa orang yang terlibat, menggunakan alat apa, dan sebagainya. Pengamatan ini dilakukan di beberapa petani lainnya sehingga dapat memperoleh pola-pola kegiatan secara umum. Hasil pengamatan dicatat dan merekam gambar menggunakan kamera photo dan video digital. Dalam kesempatan tersebut dilakukan wawancara semi terstruktur untuk mengkonfirmasikan hasil pengamatan tadi. Untuk kepentingan data 
kuantitatif digunakan kuesioner model tertutup.

Validitas menunjukkan sejauhmana suatu alat pengukur itu mengukur apa yang ingin diukur. Dalam penelitian ini cara yang digunakan untuk menguji validitas alat ukur adalah validitas konstruk, yaitu menyusun tolak ukur operasional dari suatu kerangka konsep dan teori. Upaya yang dilakukan adalah membuat tolok ukur berdasarkan kerangka konsep yang diperoleh dari beberapa kajian pustaka, berkonsultasi dengan berbagai pihak yang dianggap menguasai materi yang akan diukur, membuat kuesioner penelitian, dan menetapkan lokasi uji. Instrumen ini telah diuji di Kampung Hink Distrik Warmare dan Kampung Bremi Distrik Manokwari Utara dengan jumlah responden 30 orang petani. Langkah pengujian yaitu membuat tabulasi skor untuk setiap nomor pertanyaan untuk setiap responden dan pengujian validitas menggunakan rumus korelasi Product Moment yang hasilnya disajikan dalam Tabel 2.

Tabel 2. Hasil Uji Validitas Instrumen
Rumus yang digunakan adalah: 2(r.tt)

$$
\text { r-total }=\frac{--------}{1+r . t t}
$$

Keterangan:

$r$-total $=$ angka realibilitas keseluruhan

item atau koefisien realiabilitas

r.tt = angka korelasi belahan pertama dan belahan kedua.

Nilai Reliabilitas Guttman SplitHalf adalah $0,756 \geq$ r.tabel. Hal ini menunjukkan bahwa alat ukur tersebut mempunyai reliabilitas tinggi.

Hasil data kualitatif selanjutnya dibahas menggunakan pendekatan analisis teori: fungsional struktural, perubahan sosial, relativisme budaya, dan ekologi manusia; sedangkan data kuantitatif menggunakan analisis statistik faktorial.

\section{HASIL DAN PEMBAHASAN}

Data kualitatif terbagi menjadi pola pemenuhan kebutuhan pangan dan pola pertanian masyarakat Arfak.

\begin{tabular}{lll}
\hline No. & Peubah & Kisaran Koefisien Korelasi \\
\hline 1. & Kebutuhan Belajar $(X 1)$ & $0,76^{* *}-0,80^{* *}$ \\
2. & Nilai-nilai Budaya $(X 2)$ & $0,45^{*}-0,67^{* *}$ \\
3. & Sikap terhadap penyuluh $(X 3)$ & $0,64^{* *}-0,76^{* *}$ \\
4. & Karakteristik Petani $(X 4)$ & $0,66^{* *}-0,74^{* *}$ \\
5. & Atribut Inovasi $(X 5)$ & $0,48^{*}-0,80^{* *}$ \\
6. & Saluran Komunikasi $(X 6)$ & $0,56^{*}-0,62^{* *}$ \\
7. & Tahap Pengetahuan $(Y 1)$ & $0,63^{* *}-0,75^{* *}$ \\
8. & Tahap Persuasi $(Y 2)$ & $0,54^{*}-0,66^{* *}$ \\
9. & Tahap Keputusan $(Y 3)$ & $0,56^{*}-0,73$ \\
\hline Keterangan: berhuruftebal adalah instrumen dalam penelitian ini \\
\multicolumn{3}{c}{$*$} \\
& $*$ Nyata pada $\alpha_{0,05}$ dan $*$ nyata pada $\alpha_{0,01}$
\end{tabular}

Reliabilitas adalah menunjukkan sejauhmana suatu alat pengukur dapat dipercaya atau dapat diandalkan dalam mengukur gejala yang sama dalam waktu yang berbeda. Hal yang sama dengan uji validitas dilakukan pada tempat dan responden yang sama. Pengujia reliabilitas alat ukur menggunakan teknik belah dua, yaitu mengkorelasikan jawaban belahan pertama (ganjil) dan belahan kedua (genap).

\section{Pola Pemenuhan Kebutuhan Pangan}

Kegiatan sehari-hari masyarakat suku Arfak masih bertujuan untuk memenuhi kebutuhan hidup pokok atau dasar terutama pangan, selanjutnya; papan, dan sandang. Untuk memenuhi kebutuhan tersebut dilakukan melalui sarana yakni memanfaatkan sumberdaya yang tersedia di sekitar, dan mengintroduksi produk-produk 
yang tidak diproduksi oleh lingkungan mereka. Bagi suku-suku yang masih tinggal terpencil, jauh dari kota Manokwari, masih mengandalkan kekuatan sumberdaya setempat. Terpencil dalam hal geografis dan sulit dijangkau oleh kendaraan atau transportasi darat dan udara.

Pada umumnya bahan makanan yang dikonsumsi masyarakat Arfak seharihari adalah ubi jalar (batatas), keladi, kentang, dan jagung; kadang kala beras. Batatas dipilih yang besar untuk dimakan sendiri dan dijual, sedangkan yang kecil diberikan kepada ternak babi.

Bertani adalah kegiatan utama yang menghasilkan bahan pangan dan merupakan mata pencaharian utama bagi masyarakat Arfak. Umumnya mereka menanam ubiubian seperti ubi jalar, keladi, dan ubi kayu sebagai bahan makanan pokok. Namun demikian masyarakat Arfak yang tinggal di Distrik Warmare menanam padi ladang, pola usaha tani campuran tetap dilakukan yaitu antara tanaman pangan dengan sayursayuran. Walaupun mereka tinggal dekat dengan pemukiman transmigrasi teknik pertanian masih secara tradisional, sehingga produksi relatif rendah. Produksi padi hanya dikonsumsi sendiri, sedangkan komoditi lainnya kebanyakan dijual ke pasar. Gabah dibawa ke kampung milik eks transmigran yang telah memiliki mesin penggilingan padi.

Masyarakat Arfak sudah terbiasa memelihara ternak babi, namun bukan bertujuan komersial seperti kegiatan produksi di atas, melainkan untuk mas kawin, membayar tuntutan adat, pesta adat, dan dijual atau barter dengan mas kawin lainnya.

\section{Pola Pertanian}

Mata pencaharian utama masyarakat Arfak adalah bertani ladang berpindah. Pola bertani tersebut sudah berlangsung lama secara turun temurun dalam rangka mempertahankan kehidupan mereka. Ladang berpindah didukung oleh kondisi geografis lereng berbukit dan adanya kewajiban memanfaatkan lahan warisan agar tidak terjadi sengketa kepemilikan. Perbedaan geografis (dataran rendah dataran tinggi) memiliki jenis komoditi atau usahatani yang berbeda. Misalnya Distrik Warmare (dataran rendah sampai sedang) selain menanam komoditi pangan pokok masyarakat Arfak juga menanam padi ladang. Introduksi tanaman padi akibat daerah itu dekat dengan pemukiman transmigrasi. Petani di Warmare sering belajar dengan petani transmigran, namun yang mampu diadopsi hanya sebagian kecil.

Selain memiliki ladang di hutan sebagai kegiatan pertanian utama, juga memanfaatkan halaman rumah untuk ditanam sayur-mayur yang akan dijual di pasar. Kebun dekat rumah mudah dijaga dari serangan hama babi dan cepat panen. Produksi pertanian ini untuk kebutuhan atau konsumsi sendiri dalam keluarga, dan sebagian dijual di pasar guna mendapatkan uang tunai. Mahalnya biaya transportasi pengangkutan hasil pertanian merupakan kendala utama untuk mendapatkan pendapatan petani Arfak yang lebih baik.

\section{Teknologi dan Pengetahuan Rotasi Kebun}

Teknologi rotasi kebun bagi masyarakat Arfak memiliki makna kesuburan tanah. Secara naluri petani Arfak akan pindah ladang bila hasil kebun sudah tampak berkurang, berproduksi selama 2-3 tahun. Alasan melakukan ladang berpindah adalah Bila tanah tersebut terus digarap akan tandus yang menyebabkan longsor dan tidak subur lagi. Istilah mereka, "Kalau mama diolah terus, air susunya akan habis, maka mama akan mati." Tanah bagi masyarakat Arfak adalah "ibu" yang memberikan mereka "air susu" atau kehidupan; Tanah yang dimiliki secara turun temurun harus digarap oleh keturunannya sehingga tidak diambil alih oleh orang lain. Kebun lama dibiarkan (masa "bera") selama 3-10 tahun. Sebagai tanda kebun segera bisa diolah adalah dengan melihat pertumbuhan pohon tanaman: Alnov (Dodonea viscose Jack), 
Bikiwom, dan pohon Weimu bila tinggi mencapai 2-4 meter, lumut-lumut sudah banyak menempel, maka lahan tersebut sudah subur untuk digarap kembali.

Pelestarian hayati. Masyarakat Arfak mengenal pembagian wilayah tempat mereka mencari kehidupan sehari-hari. Kawasan bahamti adalah hutan asli yang tidak bisa diganggu untuk ladang/kebun. Kawasan nimahanti adalah bekas kebun yang ditinggalkan (masa bera) selama 10 20 tahun, pohonnya sudah besar mendekati kawasan bahamti. Kawasan susti adalah kawasan pengelolaan yang bisa digarap sebagai ladang/kebun. Kawasan situmti, adalah bekas kebun betatas, dekat dengan perkampungan atau halaman rumah (Gambar 2).

Ketersediaan pangan. Luasan

ladang masyarakat Arfak dikenal dengan tanaman pangan campuran antara lain: labu, jagung, kacang buncis, ketimun, bayam, fitsai, selada, tebu, ubi kayu/kasbi, kentang, daun bawang, tebu, ubi jalar (batatas) dan keladi. Terutama tanaman ubi jalar dan keladi mutlak harus ada setiap membuka ladang/kebun karena merupakan makanan pokok mereka.

\section{Teknologi Ketahanan Pangan}

Terdapat tiga kewaspadaan yang dilakukan oleh petani Arfak untuk ketahanan pangan sampai saat ini yaitu:

Waspada tiga musim tanam. Musim tanam dihitung berdasarkan mulainya musimkering, karena saat itu baik untuk kegiatan pembabatan, penebangan pohon, dan pembakaran. Dikenal tiga musim membuka lahan yaitu musim kecil, musim sedang, dan musim besar. Musim kecil jatuh pada bulan Maret yaitu memperkirakan tidak akan hujan selama tiga minggu ke depan. Musim sedang pada bulan Mei, dan musim besar selama tiga bulan (Agustus, September, Oktober).

Waspada pola tanam. Pola tanam campuran dilakukan dalam satu hamparan lahan. Masing-masing tanaman ditanam secara berurutan sesuai dengan umur tanaman. Labu ditanam ketika tanah masih hangat bekas pembakaran. Jagung, kacang buncis, kentang, dan terakhir ditanam ubi jalar sebagai makanan pokok.

Waspada lumbung alam. Masyarakat Arfak panen ubi jalar sesuai dengan kebutuhan dalam keluarga sehingga memiliki cadangan pangan 1-2 tahun. Pada hari pertama digali pada satu sisi dengan cara pelan-pelan dan menyisakan akar-akar, kemudian lubang bekas galian ditutup kembali dengan tanah supaya akar membentuk umbi baru. Panen pada hari berikutnya pada tiga sisi yang lain, dan seterusnya secara siklus. Jadi, satu rumpun ubi jalar bisa dipanen selama satu tahun: 4 sisi $\mathrm{x} 3$ bulan $=12$ bulan). Terjadinya kelaparan di Kabupaten Yahukimo pada Desember 2005 diduga masyarakat di sana mulai meninggalkan kearifan lokal yang sudah dianut sejak lama, sementara inovasi anjuran dari pemerintah belum begitu mantap dipraktekkan.

Adanya kearifan lokal masyarakat Arfak diperkuat oleh Susanto dan Suparlan (1989:396-398) bahwa ketahanan pangan lebih disebabkan oleh adanya potensi ketahanan sosial budaya pada kehidupan masyarakat tradisional atau etnik tertentu. Ketahanan sosial budaya dalam hal pangan pokok diartikan terciptanya kondisi sosial dan budaya masyarakat yang stabil dalam proses kehidupan rutin sehari-hari dimana kebiasaan pangan (food habits) yang menyangkut pangan pokok relatif tidak tergoyahkan walaupun terjadi goncangangoncangan ekonomi, politik dan persediaan pangan pokok yang ada dalam masyarakat.

\section{Faktor-faktor Pendorong dan Penghambat Adopsi Inovasi}

Hasil analisis faktor pada Tabel 3 menunjukkan bahwa rasa empati, keterbukaan, dan keinovatifan adalah nilai sosial esensial yang dimiliki oleh petani Arfak. Sebaliknya memiliki nilai pelengkap atau nilai sosial yang bisa menghambat inovasi seperti pesimis, irasional, dan tidak berani ambil resiko. Memiliki rasa empati 
menunjukkan kemampuan masyarakat Arfak memproyeksikan dirinya ke dalam peran orang lain. Masyarakat yang memiliki empati tinggi akan mampu untuk membayangkan diri mereka sama dengan orang lain yang misalnya mengalami kemajuan, cepat beradaptasi terhadap perubahan yang datang dari luar, dengan sendirinya mau berinovasi pada kegiatan pertaniannya.
Beternak babi bagi masyarakat Arfak adalah untuk kepentingan sosial dan budaya. Penggunaan mesin penyemprot hama belum diterima karena rumit pemeliharaannya dan perlu bahan bakar yang harus mengeluarkan tenaga dan dana dalam pengoperasiannya.

\section{KESIMPULAN}

Tabel 3. Faktor Pendorong dan Penghambat Adopsi Inovasi Berdasarkan Dimensi Nilai-nilai Sosial dan Atribut Inovasinya $(n=100)$

\begin{tabular}{|c|c|c|c|c|}
\hline \multirow[t]{2}{*}{ No } & \multicolumn{2}{|l|}{ Nilai-nilai Sosial } & \multicolumn{2}{|l|}{ Atribut Inovasi } \\
\hline & Dimensi & Nilai Komponen & Dimensi & $\begin{array}{l}\text { Nilai } \\
\text { Komponen }\end{array}$ \\
\hline 1. & Empati & $0,77^{*}$ & Kesesuaian (Kompatibilitas) & $0,51^{*}$ \\
\hline 2. & Keterbukaan pd perubahan & $0,54 *$ & $\begin{array}{l}\text { Bisa dibuktikan } \\
\text { (Obsevabilitas) }\end{array}$ & $0,50 *$ \\
\hline 3. & Keinovatifan & $0,50^{*}$ & Kerumitan (Kompleksitas) & 0,44 \\
\hline 4. & Keberanian ambil resiko & 0,49 & Mudah dicoba(Triabilitas) & 0,41 \\
\hline 5. & Rasionalitas & 0,48 & Menguntungkan & 0,35 \\
\hline 6. & Optimis & 0,40 & Ketersediaan inovasi & 0,23 \\
\hline
\end{tabular}

Keterangan: Bila nilai komponen > = 0,5 artinya, dimensi tersebut esensial

Tentang atribut inovasi memperlihat-kan dimensi kompatibilitas (kesesuaian) dan observabilitas (pembuktian) adalah faktor penting (esensial) melekat pada inovasi yang diterima oleh petani Arfak selama ini. Atribut lainnya (kompleksitas, triabilitas, keuntungan relatif dan ketersediaan inovasi) adalah faktor pelengkap. Artinya, dua atribut inovasi tersebut telah direspons dengan baik oleh petani Arfak, sedangkan empat atribut lainnya seperti ketersediaan inovasi, keuntungan relatif, triabilitas/mudah dicoba, dan kompleksitas/kerumitan kurang melekat pada inovasi yang telah diterima petani Arfak. Inovasi yang sesuai adalah inovasi yang mudah diadaptasi oleh masyarakat yang akan diberikan inovasi. Inovasi yang masuk ke petani Arfak harus memiliki kesesuaian dengan kondisi sosial, budaya, dan kemampuan ekonomi masyarakat. Inovasi menanam apel adalah tidak sesuai dengan budaya kerja masyarakat Arfak karena memerlukan ketelitian dan kerumitan.
Konsep ladang berpindah bagi petani Arfak bermakna sebagai kesuburan tanah,pelestarian hayati, dan ketersediaan pangan. Selain memiliki konsep pelestarian lingkungan, petani Arfak memiliki konsep "Ketahanan Pangan" yaitu kewaspadaan terhadap tiga waktu tanam, tanaman campuran (multicrop), dan lumbung alam.

Faktor-faktor nilai sosial pendorong pengembangan petani Arfak adalah kemampuan berempati, keterbukaan, inovatif sehingga memiliki kemampuan menyesuaikan (compatability) dan mengamati (observability) setiap inovasi yang diterimanya. Namun petani Arfak memiliki kekuatan pengganggu yang ikut menghambat proses adopsi inovasi yaitu pesimistis, irasional, dan tidak berani mengambil resiko. Faktor pengganggu tersebut bisa dikurangi melalui inovasi yang mudah dan murah diperoleh serta bisa diuji coba. 


\section{DAFTAR PUSTAKA}

Adimihardja, K. 2004. Sistem Pengetahuan dan Teknologi Lokal, dalam Pembangunan Berkelanjutan di Indonesia. Bandung: Humaniora.

Cohen, D. dan L. Prusak. 2001. In Good Company: How Social Capital Makes Organization Works. Harvard Business Press.

Soedijanto. 2004. Menata Kembali Penyuluhan Pertanian di Era Pembangunan Agribisnis. Jakarta, Departemen Pertanian.

Susanto, D. dan S. Suparlan. 1989. "Keanekaragaman Makanan Pokok di Indonesia dan Ketahanan Sosial Budayanya". Prosiding Widyakarya Pangan dan Gizi, Jakarta 1-3 Juni 1988, Penyunting: Setijati D. Sastrapradja dan Muhilal. Jakarta: Lembaga Ilmu Pengetahuan Indonesia.

Untung, K. 1996. "Kebijakan Nasional Pembangunan Pertanian Berkelanjutan Berwawasan Lingkungan". Bahan Ceramah pada Peringatan Hari Pangan Sedunia di Purbalingga, 17 Oktober 1996. Staf Ahli Menteri Negara Lingkungan Hidup. 